\title{
Induced sputum in children: feasibility, repeatability, and relation of findings to asthma severity
}

\author{
Nicola M Wilson, Peter Bridge, Antonio Spanevello, Michael Silverman
}

\begin{abstract}
Background-The collection of induced sputum provides a non-invasive method of investigating airway inflammation. Few studies have been performed in children, so a study was undertaken to determine the feasibility of sputum induction, the repeatability of eosinophil counts and sputum eosinophil cationic protein (ECP) levels, and the relation of these to current asthma severity. For comparison, serum ECP levels were also measured.

Methods-In a cross sectional study of children aged 5-15 years, 27 healthy children and 60 with asthma underwent sputum induction using inhaled nebulised hypertonic saline. The whole sputum sample was used for analysis. Ten children with stable asthma repeated the procedure within 10 days.
\end{abstract}

Results-A satisfactory sample $(>500$ non-squamous cells) was obtained in $61 \%$ of children with asthma and in $60 \%$ of healthy controls. The limits of agreement within subjects ranged from a 0.68 to 2.8 fold difference for eosinophil differential counts and from 0.38 to 4.4 fold for sputum ECP. Despite a median of $42 \%$ squamous cells, significant differences were found between asthma and healthy controls for the eosinophil differential count $(p=0.0004)$, total eosinophil counts $(p=0.03)$, and sputum ECP level ( $p=$ $0.0001)$. Overall, there was no correlation between any marker of airway inflammation and asthma severity, however expressed, including lung function.

Conclusions-Sputum induction is only possible in a proportion of children. The repeatability of sputum cell counts and ECP levels, measured in a small number of children, was similar to that reported in adults. Sputum analysis revealed no evidence of airway inflammation in a number of highly symptomatic children with asthma.

(Thorax 2000;55:768-774)

Keywords: asthma; sputum; children

Dr N M Wilson, Depa

Brompton and Harefield

NHS Trust, London

SW3 6NP, UK

email:

n.wilson@rbh.nthames.nhs.uk

Received 29 October 1999 Returned to authors

31 January 2000

Revised version received

30 May 2000

Accepted for publication

1 June 2000

Asthma in both adults and children is associated with airway inflammation. ${ }^{12}$ Inhaled corticosteroids are widely used to treat airway inflammation in asthma, but the relation between the dose needed to control symptoms, reduce inflammation or, in the long term, to prevent airway remodelling is not known.
Treatment is mostly on an empirical basis and it is rarely known whether or not the optimum anti-inflammatory effect has been achieved. Evidence of airway inflammation can be found even in those with mild or well controlled symptoms. ${ }^{3}$ There is an obvious need for a non-invasive means of assessing airway inflammation, particularly in children in whom direct methods of assessment are rarely possible.

The assessment of induced sputum can provide a useful tool for monitoring airway inflammation. ${ }^{34}$ Airway inflammation, reflected by an increase in the eosinophil differential cell count, eosinophil cationic protein (ECP), and inflammatory cytokines, has been demonstrated in sputum induced by inhalation of hypertonic saline. ${ }^{4}$ There is limited information concerning the use of induced sputum in children, ${ }^{5-7}$ although considerable numbers of studies have confirmed the reliability of the method in adults and have shown a reduction in inflammation following treatment with inhaled corticosteroids (ICS). ${ }^{18}$

The purpose of this study was threefold. Firstly, to assess the feasibility of inducing sputum in children. For the result of a test to have general application it must be possible for it to be performed by the majority of the subjects attempting it, without bias in the different groups being studied. Secondly, we were interested in the repeatability of this method in children. This was assessed for eosinophils, both within a single sample by one observer and between two observers, and also for cell counts and sputum ECP levels within subjects with stable asthma by repeating the test twice within 10 days. Our third objective was to investigate the relation between evidence of airway inflammation and the level of current symptoms in children who were treated with a wide range of inhaled corticosteroids (none, low dose, high dose). To do this a daily asthma record was kept of symptoms, bronchodilator use, and twice daily peak expiratory flow rates for two weeks before sputum was induced. For comparison, sputum was also induced in healthy control children of a similar age. Since several groups have advocated the use of serum ECP as an indirect marker of airway inflammation, this was also measured. ${ }^{9} 10$

\section{Methods}

SUBJECTS

Children with asthma were recruited from the Paediatric Asthma Clinic of the Hammersmith Hospital if they were either currently symptomatic despite treatment with ICS or they were 
not being treated with ICS but had experienced symptoms in the preceding three months. In the latter category, some children with episodic symptoms were included. No child was taking any other anti-inflammatory agent. All had typical asthma with documented variable bronchoconstriction and no other diagnosis.

Healthy controls were recruited from siblings of children attending one of the paediatric clinics (including the asthma clinic) or from children of staff. A parent was interviewed and a paediatrician examined the child to confirm the lack of past or present lower respiratory disease. Atopic children were not excluded. Any child of seven years or older was approached if they fulfilled these criteria. In addition, three children aged less than six years were recruited as they were, unusually for their age, able to perform reproducible spirometric tests.

No child was tested within two weeks of a clinical viral infection.

STUDY PROTOCOL

Children with asthma kept an asthma diary in which symptoms, bronchodilator usage, and twice daily peak flow (PEF) were recorded for two weeks immediately before attending the paediatric asthma laboratory for (a) spirometric tests (Vitalograph, Compact, Buckingham, UK), (b) hypertonic saline inhalation and sputum induction (if the forced expiratory volume in one second $\left(\mathrm{FEV}_{1}\right)$ was $>70 \%$ predicted), (c) skin prick tests to five common allergens (house dust mite, cat, dog, grass and feathers, Pharmacia, Uppsala, Sweden), and (d) venepuncture for eosinophil count and measurement of total IgE and ECP levels (RIA, Pharmacia) after application of local anaesthetic cream.

Healthy control children underwent spirometric tests, hypertonic saline inhalation, sputum induction, and skin prick tests but did not have blood taken.

\section{REPEATABILITY}

The between observer repeatability was calculated by comparing the differential cell counts between the two independent observers counting the same slides, blind to each others' results. Both asthma and control samples were used.

To obtain the within subject repeatability, 10 asthmatic subjects with stable asthma were asked to return within 10 days to undergo the identical protocol. The repeat counts were made blind to the initial findings. Only subjects with no change in medication or symptom severity were included.

The within sample repeatability was determined by comparing the results of one observer from the original set of slides with the results from a different set of slides obtained from the same sputum sample, counted independently under blind conditions, by the same observer, from 15 individuals selected at random from the asthma samples.
ASSESSMENT OF ASTHMA SEVERITY

The functional residual severity was defined as the level of symptoms irrespective of treatment. ${ }^{11}$ The percentage of symptom free days and the percentage of disturbed nights and days with exercise induced symptoms were noted from the records of the asthma diary kept for two weeks before the investigation.

The severity of the asthma was also assessed according to the current treatment: (i) no ICS (non-ICS); (ii) ICS low dose (up to $400 \mu \mathrm{g} /$ day); (iii) ICS high dose ( $>400 \mu \mathrm{g} /$ day).

\section{SPUTUM INDUCTION}

Hypertonic saline (4.5\%) was inhaled through a mouth piece and a large two-way valve (Hans Rudolph Inc, Kansas, USA) connected to a Timeter nebuliser (Oregon, Pike, Pennsylvania, USA) set at maximum output (at least $2 \mathrm{ml} / \mathrm{min}$ ). Inhalations were carried out for doubling periods of time, starting at two minutes and continued up to a maximum period of 16 minutes. After each inhalation period the child was asked to cough and expectorate into the provided pot. The $\mathrm{FEV}_{1}$ was measured after each inhalation to screen for bronchoconstriction. The inhalations were repeated up to a cumulative total time of 30 minutes, or until a sputum sample was obtained. If there was no sample by then, nebulised salbutamol $(2.5 \mathrm{mg})$ was given to prevent bronchoconstriction. The hypertonic saline inhalations were then resumed for a further period of 15 minutes without the valve to increase the inhaled dose of aerosol in a further attempt to induce a sample.

\section{SAMPLE PROCESSING}

The sputum and saliva samples were processed within half an hour of production. Sputum samples were considered satisfactory if at least 500 non-squamous cells could be counted.

The entire sputum volume was measured and an equal volume of dithiothreitol $0.1 \%$ (DTT, Sputolysin; Calbiochem Corporation, San Diego, California, USA) was then added and the whole sample was mixed at $37^{\circ} \mathrm{C}$ for 20 minutes to ensure homogenisation. The sample was centrifuged at $1000 \mathrm{~g}$ for 10 minutes and aliquots of the supernatant were taken and stored at $-70^{\circ} \mathrm{C}$ for a later biochemical analysis. The pellet was resuspended in a volume of phosphate buffered saline (PBS) equal to the previous volume of DTT to obtain a total cell count in a Neubauer haemocytometer. Cell viability was assessed by the trypan blue exclusion method, the blue cells being considered dead. The cell suspension was then adjusted to $1.0 \times 10^{6}$ cells $/ \mathrm{ml}$ and $100 \mu 1$ of cell suspension were placed into the cups of a Shandon 11 cytocentrifuge (Shandon, Southern Instruments, Sewickley Park, Pennsylvania, USA). The cytospins were prepared at $450 \mathrm{~g}$ for six minutes. The slides were air dried and stained with May-Grunwald-Giemsa stain. The mean of 500 non-squamous cells, counted by two independent observers, was used to obtain the differential cell count.

Sputum supernatant was analysed in batches for ECP (RIA, Pharmacia). The upper limit of 
Table 1 Feasibility of sputum sample production and comparison of cellular morphology and sputum ECP between asthma and healthy controls

\begin{tabular}{|c|c|c|c|c|c|c|c|c|c|c|}
\hline & $\begin{array}{l}\text { No. of } \\
\text { subjects }\end{array}$ & Age (years) & $\begin{array}{l}\text { Mean (SD) } \\
F E V_{1}(\%)\end{array}$ & $\begin{array}{l}\text { Skin prick test } \\
\text { positive (\%) }\end{array}$ & $\begin{array}{l}\text { Sample } \\
\text { productiont (n) }\end{array}$ & $(\%)$ & $\begin{array}{l}\text { Eosinophils } \\
\left(\times 10^{6} / \mathrm{ml}\right)\end{array}$ & $(\%)$ & $\begin{array}{l}\text { Total cell count } \\
\left(\times 10^{6} / \mathrm{ml}\right)\end{array}$ & $\begin{array}{l}E C P \\
(\mu g / l)\end{array}$ \\
\hline Control & 27 & $9.8(8.4-11.9)$ & $91(12)$ & 38 & 17 & 61 & $0(0-0)$ & $0(0-0)$ & $2.4(0.9-2.8)$ & $8.8(2-25)^{\star}$ \\
\hline Asthma & 60 & $10.2(8.4-11)$ & $91(21)$ & 62 & 36 & 60 & $0.04(0-0.4)$ & $0.02(0-1.3)$ & $2.4(1.7-4.3)$ & $83(34-258)^{\star}$ \\
\hline $\mathrm{p}$ value & & 0.59 & 0.9 & 0.02 & & & 0.03 & 0.004 & 0.34 & $<0.001$ \\
\hline
\end{tabular}

Values as median (IQR) except * geometric mean. †Eight other children were unable to cooperate with the technique.

measurement was $200 \mu \mathrm{g} / 1$. This was expressed as concentration $/ \mathrm{ml}$ of undiluted supernatant (upper limit of detection $400 \mu \mathrm{g} / \mathrm{l}$ ).

Blood samples, collected into plain glass, were allowed to clot at room temperature for one hour and were then centrifuged for 10 minutes at $1000 \mathrm{~g}$ before the serum was removed, frozen at $-20^{\circ} \mathrm{C}$, and stored for later analysis of serum ECP levels, total $\mathrm{IgE}$, and house dust mite specific IgE (RAST).

The project was approved by the Hammersmith Hospital ethics committee and informed written consent was obtained from a parent and also the child if appropriate.

STATISTICAL ANALYSIS

Minitab software (Release 12, State College, USA) was used to perform statistical analysis. For differential and total cell counts the data are presented as medians and interquartile range (IQR). Because of markedly skewed data distribution in cell counts, the Kruskal-Wallis ANOVA was used to make comparisons. Comparisons of cell counts between groups were made with a Mann-Whitney test, with an adjustment for multiple comparisons. Both tests adjusted for tied values. Differences in sputum and serum ECP concentrations between groups were compared using the Student's $t$ test after log transformation. Correlations between variables were made using Spearman's rank correlation.

To demonstrate the limits of agreement of repeated values of eosinophil differential counts, eosinophil numbers, and total cell counts Bland and Altman plots were constructed..$^{12}$ In order to overcome the problem of the relation between the SD of the difference and its mean value, the mean values were plotted against the ratio of the two values rather than the differences. Because of the small numbers, the range of the ratios of repeat values is given. The intraclass correlation coefficient (or coefficient of reliability, R) was calculated (i) using the SD of the ratios for eosinophil differential count and number, and the total cell counts; and (ii) the SD of differences for $\log$ ECP to determine the proportion of the variances between the compared pairs to the total variance. In addition, the geometric coefficient of variation was calculated for the non-normally distrib-

Table 2 Symptom severity in preceding two weeks in children with asthma, with and without treatment with inhaled corticosteroids (ICS)

\begin{tabular}{llllll}
\hline & $\begin{array}{l}\text { No. of } \\
\text { subjects }\end{array}$ & FEV $(\%)$ & $\begin{array}{l}\text { Symptomatic days } \\
(\%)\end{array}$ & $\begin{array}{l}\text { Nocturnal } \\
\text { symptoms (\%) }\end{array}$ & EIA (\%) \\
\hline No ICS & 21 & $93(13)$ & $33(15-80)$ & $14(0-33)$ & $15(0-32)$ \\
ICS & 15 & $89(25)$ & $63(29-100)$ & $25(0-65)$ & $36(18-78)$ \\
p value & & 0.98 & 0.07 & 0.53 & 0.04 \\
\hline
\end{tabular}

uted variables and the coefficient of variation for $\log$ ECP. ${ }^{13}$

\section{Results}

FEASIBILITY OF SPUTUM SAMPLE PRODUCTION Eight children of median (range) age 7 (5-13) years were unable to cooperate with the sputum induction protocol; 34 of the remaining $87(39 \%)$ were unable to produce a satisfactory sputum sample (defined as containing at least 500 non-squamous cells), the majority having a dry cough only (table 1 ). There was no age difference between those who produced a sample (median 10.1 years (range 5-15)) and those who did not (median 9.6 years (range $5-15)$ ). As only two children under seven years were invited to take part on the grounds that they could expectorate to order and were exceptionally good at performing spirometric tests for their age, feasibility in the younger age was not fairly assessed. There was no difference in age, asthma severity, or treatment category between those who did and those who did not produce a sputum sample. There was no difference in the proportion of children able to produce a sample between the asthma and control groups (36/60 (60\%) versus $17 / 27(61 \%)$, table 1$)$.

Of the 36 children with asthma from whom a sputum sample was obtained, 15 were treated with ICS (seven low dose and eight high dose) and 21 were treated with bronchodilators only (non-ICS); four of the ICS group were also taking a long acting bronchodilator. Symptom severity in the preceding two weeks in the two groups is shown in table 2 . Five of the $43 \mathrm{spu}-$ tum samples were obtained only after the removal of the Hans Rudolph valve (leading to a prolonged inhalation period and increased lung dose of hypertonic saline).

Cell viability ranged between $50 \%$ and $89 \%$ with no significant difference between asthmatic and control children (median values $70 \%$ and $67 \%$, respectively).

SQUAMOUS CELL CONTAMINATION

Squamous cell contamination was high, the median proportion of squamous cells being $42 \%$ (IQR 26-50\%). The proportion of squamous cells was unrelated to the eosinophil count or the level of ECP in the supernatant. There was no difference between asthmatic and healthy children $(\mathrm{p}=0.66)$.

\section{REPEATABILITY}

Within sample and within observer

The relation between values for eosinophil differential counts in both comparisons was best when counts were high but discrepancies were seen between observers and within samples with low counts (table 3 ). 
Table 3 Repeatability: intraclass correlation coefficients and geometric coefficients of variation

\begin{tabular}{lllll}
\hline & $\begin{array}{l}\text { Eosinophil } \\
\text { differential count }\end{array}$ & $\begin{array}{l}\text { Eosinophil total } \\
\text { count }\end{array}$ & $\begin{array}{l}\text { Total cell } \\
\text { count }\end{array}$ & ECP \\
\hline $\begin{array}{c}\text { Intraclass correlation coefficient }(R) \\
\text { within subject (between days) }\end{array}$ & 0.93 & 0.90 & 0.63 & 0.92 \\
$\begin{array}{c}\text { between observer (two observers) } \\
\text { within sample (two preparations) }\end{array}$ & 0.98 & - & - & - \\
$\begin{array}{c}\text { Geometric coefficient of variation } \\
\text { (\%) within sample }\end{array}$ & 29 & - & - & - \\
\hline
\end{tabular}

Within subject

The overall within subject repeatability (R) was satisfactory for eosinophil differential counts and total counts as well as for ECP levels but was less so for the total cell count (table 3). The limits of agreement for repeat eosinophil differential counts ranged from 0.68 to 2.4 fold (mean 1.15), for eosinophil number the range was $0.7-4.55$ fold (mean 1.6), for the total cell count it was $0.7-4.55$ fold (mean 1.16), and for ECP levels the range was $0.38-4.4$ fold (mean 1.54) (fig 1).

COMPARISON BETWEEN ASTHMATIC CHILDREN AND CONTROLS

There was a significantly higher eosinophil differential count in the sputum of children with asthma than in the controls (95\% confidence interval of difference (CI) 0.002 to 0.84 ; p = 0.004) and the sputum ECP level was significantly higher (95\% CI 0.035 to 0.21 ; $\mathrm{p}<0.0001$, table 1 ). The proportion of sputum eosinophils was not increased in the asthma ICS group compared with controls $(p=0.68)$ but the ECP concentration was significantly higher ( $p=0.004$, fig 2 ). In the non-ICS group
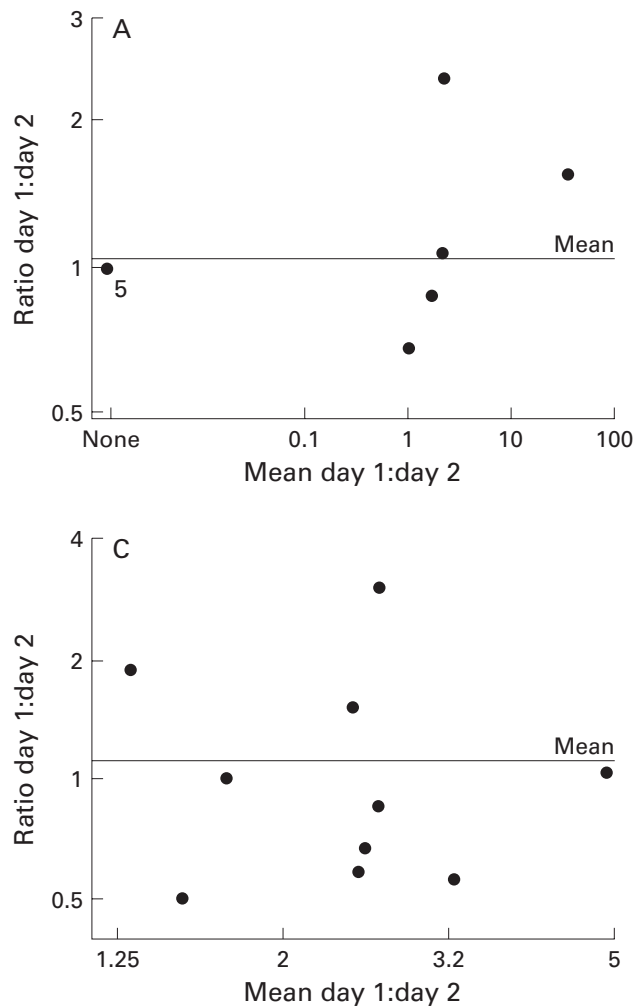

of patients both the proportion of eosinophils $(p=0.0002)$ and the ECP levels $(p<0.0001)$ were significantly higher than in controls (fig 2). There was a significant correlation in the sputum between the percentage of eosinophils and ECP levels $\left(r^{2}=0.28, \mathrm{p}<0.001\right)$. There was also a weak correlation between sputum and serum levels of ECP $\left(r^{2}=0.17, \mathrm{p}=0.03\right)$.

EOSINOPHILS, ECP LEVELS, AND ASTHMA SEVERITY The study had the ability to detect a correlation of at least 0.45 (Spearman's rank correlation coefficient) with $80 \%$ power at the 5\% level between sputum eosinophils and indices of asthma severity. For all the children with asthma (ICS and non-ICS) there was no relationship between any currently measured index of asthma severity, including lung function, and the percentage of eosinophils or sputum or serum levels of ECP (fig 3). There was no difference in $\mathrm{FEV}_{1}$ between those with any eosinophils and those with none (mean (SD) $\mathrm{FEV}_{1} 90$ (12)\% predicted versus 93 $(25) \%$ predicted; $p=0.72)$. Similarly, in children with asthma with increased values of ECP in either blood or sputum (judged by levels above either the upper quartile for asthma or the maximum values found in healthy children) there was no difference in $\mathrm{FEV}_{1}$ compared with those with normal ECP levels.

When the sputum and serum results were considered for the ICS and non-ICS groups separately, or when the ICS group was divided into high dose $(n=8)$ and low dose $(n=7)$ subgroups, there was still no relation with any
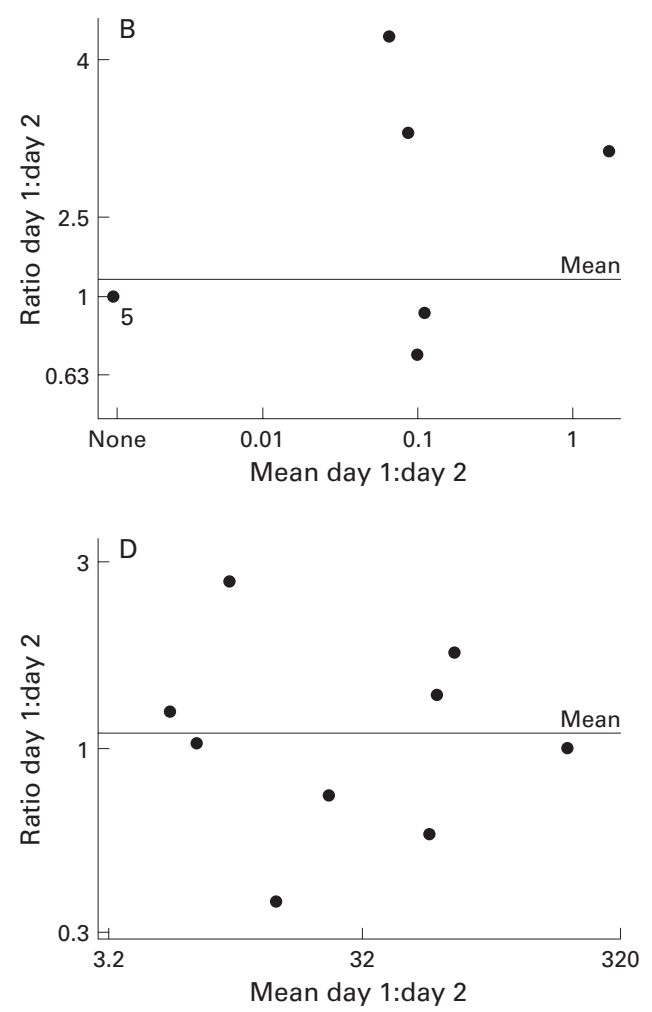

Figure 1 Range of agreement for repeat values performed twice in the same subject within 10 days for (A) eosinophil differential count (\%), (B) eosinophil number $\left(10^{6} / \mathrm{ml}\right),(C)$ total cell counts $\left(10^{6} / \mathrm{ml}\right)$, and (D) ECP ( $\left.\mu \mathrm{g} / \mathrm{l}\right)$ in sputum supernatant. 

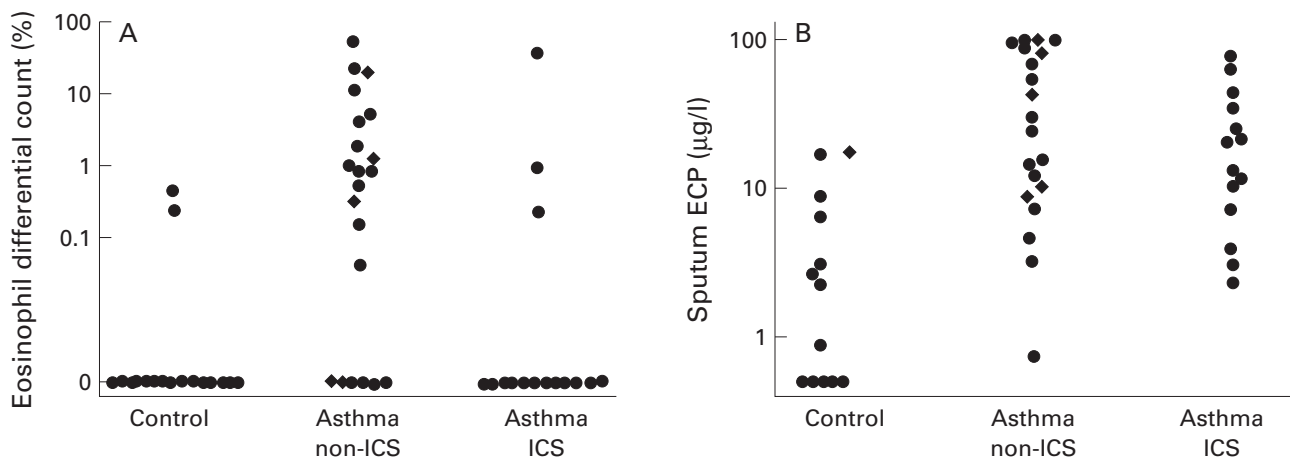

Figure 2 (A) Sputum eosinophil differential count: control versus asthma non-ICS, $p=0.003$; asthma non-ICS versus asthma ICS, $p=0.02$; control versus asthma ICS, not significant. (B) Sputum ECP levels in the three groups of subjects: control versus asthma non-ICS, $p=0.004$; control versus asthma ICS, $p<0.001$; asthma ICS versus asthma non-ICS, not significant. Diamonds represent individuals with occasional (episodic) symptoms only.
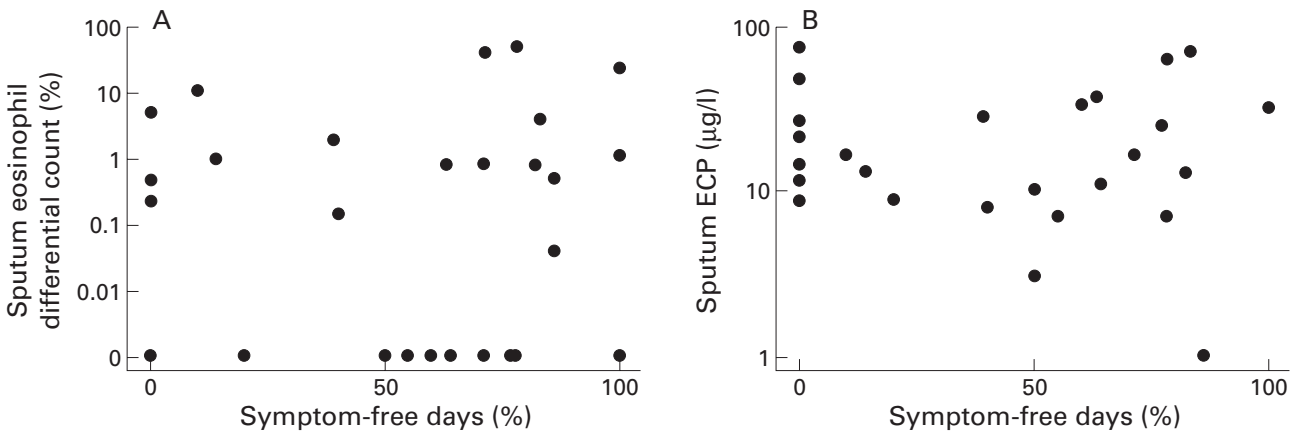

Figure 3 Relationship between (A) sputum eosinophil differential count and (B) sputum ECP levels and symptom-free days in children with asthma.

clinical index of current symptom severity, nor was there any relation between evidence of inflammation and medication category (nonICS, high or low dose ICS).

\section{Discussion}

Using this technique of sputum induction we have shown significant differences in the proportion of eosinophils and in sputum ECP levels between children with asthma and healthy children and some differences between those treated with ICS and those who were not. Fifty six percent of the children tested were able to produce a satisfactory sample. This included the small number who were unable or refused to cooperate with the protocol. This is much lower than the $92 \%$ success rate reported in a recent Australian epidemiological study ${ }^{7}$ and could be due to differences in the sputum induction method or in the criteria used to define a satisfactory sample.

Repeatability was considered in several ways. In the 10 children tested on two occasions no eosinophils were found in five on both occasions; unfortunately, only one child with very high levels was studied twice, but he showed a repeatable result. The repeatability was less good with low eosinophil levels, but this not likely to be of clinical significance where levels are within the normal range. Similarly, marked variation between observers was only seen at low eosinophil levels. Estimations of the limits of agreement and the geometric coefficient of variation of the eosinophil differential counts were also affected by the unreliability of low eosinophil values. When different slides made from a single sample were compared blind by one observer the variation in values was small, indicating that the measurement was representative of the whole sample. The intraclass correlation coefficient, which considers the contribution of the variance between measurements to the total variance, was highly acceptable in this study for sputum eosinophils and ECP levels both within subjects and between observers. Our findings, in the small numbers of repeat measurements made, were similar to those previously reported in adults. ${ }^{44}{ }^{15}$ However, the intraclass correlation coefficient is highly sensitive to subject selection and is improved by a wide variation in values between subjects, as was found in our asthmatic group. The eosinophil differential count showed a better repeatability than the total count, as has been reported previously, ${ }^{16}$ probably as the result of salivary contamination leading to variable sputum dilution. This is reflected in the increased coefficients of variation and range of agreement for total cell count and sputum ECP levels.

Considering the two asthma treatment groups separately, the asthmatic children not treated with ICS differed from controls in both eosinophil differential count and sputum ECP levels; in the ICS group the sputum ECP level was higher than in healthy children but there was no difference in eosinophil differential count. The lack of difference between controls and children treated with ICS is unlikely to be due to the small numbers in the group as eosinophils were found in only a few ICS treated children, in many of whom sputum levels of 
ECP were increased (fig 2). A similar discrepancy between the two has also been previously noted in adults ${ }^{17}$ and one possible explanation for this finding is the effect of DTT in dispersing cells, which has been shown to increase sputum levels of ECP but not to alter the cell count. ${ }^{18}$ However, this should affect both treatment groups similarly.

As we used the "whole sample" method of sputum analysis, a high proportion of squamous cells was present from inevitable salivary contamination. This is one possible explanation for the lack of eosinophils in symptomatic children with asthma treated with ICS. ${ }^{19}$ However, squamous cell contamination did not differ between ICS and non-ICS children, and is therefore unlikely to have masked real differences in cell counts.

The results of induced sputum analysis in asthmatic children have been reported in a few studies. ${ }^{35720}$ In most cases selected sputum portions, rather than the whole sample, were used. The differences in eosinophil differential counts between asthmatic and healthy controls were similar to the present study. Consideration of sputum indices and asthma severity has infrequently been reported in children, but a lack of a relationship was also noted in a population study. ${ }^{7}$ In another study eosinophils were significantly increased in those with poor control compared with those with good asthmatic control. ${ }^{3}$ The difference could either be due to the fact that children with a recent acute exacerbation were included or poor compliance with treatment led to both poor control and high eosinophil levels. In our study we excluded children who had recently been treated with oral corticosteroids and those with a recent virus infection, the most usual cause of acute exacerbations. ${ }^{21}$ In children with an acute exacerbation of asthma very high levels of both eosinophils and neutrophils were found in the sputum, but these soon fell on recovery. ${ }^{6}$

Early studies of serum ECP levels in asthma recommended its measurement as a clinical tool for monitoring airway inflammation. ${ }^{92}$ However, the relation of serum ECP levels to asthma severity is controversial. ${ }^{23}$ Our results are in accordance with others in showing a poor relationship between serum ECP levels and symptom severity. ${ }^{23}$ Indeed, we used three markers of airway inflammation but none of them related to current asthma symptoms, which was disappointing. In studies in adults the relation between airway eosinophils and asthma severity is also unclear. ${ }^{14}{ }^{25}$ On the other hand, most studies in adults and one in adolescents with severe asthma have found a correlation between lung function and inflammatory indices. ${ }^{16}{ }^{26-28}$ In contrast, as was the case for Piacentini and colleagues who studied children with mild to moderate asthma, in our study there was none. ${ }^{20}$ This could be because airway remodelling is related to chronic airway inflammation and occurs only after a prolonged period of time, so it may not be established in children. Some children with asthma that is difficult to control have surprisingly good lung function. For example, in the present study $67 \%$ of the children had an $\mathrm{FEV}_{1}$ of $>80 \%$ predicted, despite a mean of only nine asymptomatic days in the preceding two weeks.

There is still much to be learnt about the relationship between measures of inflammation, severity of asthma, and the response to anti-inflammatory treatment. The precise relationship may depend on the individual. In our group of non-ICS children we found some with very high eosinophil counts but minimal asthma symptoms (fig 3); it would be interesting to know whether this finding represents a risk factor which predicts severe symptoms. In ICS treated children high values may be a marker of treatment non-compliance. In contrast, some highly symptomatic children treated with high-dose ICS were without any evidence of airway eosinophil activity (fig 3 ). It is not clear whether this is due to difficulty in assessing asthma severity or because the relationship between airway inflammation and asthma symptoms has too many dimensions to be detected in such a simple assessment. ${ }^{27}$ The latter seems the most likely, as no relation between severity and inflammatory cells was seen when the more direct methods of bronchoalveolar lavage and bronchial biopsy were used..$^{25}$ Another possibility is that the persistence of asthma symptoms despite high dose anti-inflammatory treatment results from a factor that is independent of eosinophilic inflammation such as autonomic dysfunction.

We conclude that, of those able to cooperate with the sputum induction process, about two thirds will produce a sample that can be analysed. Since there was no difference in the ability to produce a sample between healthy children and asthmatics, with or without ICS treatment, or between children with different severity of asthma, this low feasibility rate is unlikely to invalidate studies of airway pathology in asthma. However, it has important implications for the workload entailed in research projects. Although we used a method in which there were high levels of salivary and squamous cell contamination, we were able to distinguish between asthmatic and control children, not only by total and differential eosinophil counts but also by the ECP levels in the supernatant. Sputum ECP levels but not eosinophil numbers were increased in ICS treated asthmatics with a high level of current symptoms. None of the three inflammatory markers studied (sputum eosinophils, sputum ECP, and serum ECP) was related to current symptom severity or lung function. We were unable to detect any evidence of eosinophilic airway inflammation in several children with persisting asthma. In these children it is not clear whether or not an increase in their antiinflammatory treatment is indicated. On the other hand, those with clear evidence of airway inflammation require an increase in, or better supervision of, anti-inflammatory treatment.

This study was supported by the National Asthma Campaign, $\mathrm{UK}$ and Salvatore Maugeri Foundation, Italy. We are grateful to Caroline Dore (Statistical Consultancy Service, Imperial School of Medicine) for statistical advice.

1 Djukanovic R, Wilson JW, Britten KM, et al. Effect of an inhaled corticosteroid on airway inflammation and symptoms in asthma. Am Rev Respir Dis 1992;145:669-74. 
2 Busse W, Banks SS, Larsen GL. Childhood- versus adult-onset asthma Am ₹ Respir Crit Care Med 1995;151 adult-on

3 Cai Y, Carty K, Henry RL, et al. Persistence of sputum eosinophilia in children with controlled asthma when compared with healthy children. Eur Respir F 1998;11:848-53.

4 Pin I, Gibson PG, Kolendowicz R, et al. Use of induced sputum cell counts to investigate airway inflammation in asthma. Thorax 1992;47:25-9.

5 Pin I, Radford S, Kolendowicz R, et al. Airway inflammation in symptomatic and asymptomatic children with methacholine hyperresponsiveness Eur Respir F 1993;6:1249-56.

6 Twaddell SH, Gibson PG, Carty K, et al. Assessment of airway inflammation in children with acute asthma using induced sputum. Eur Respir f 1996;9:2104-8.

7 Gibson PG, Wlodarczyk JW, Hensley MJ, et al. Epidemiological association of airway inflammation with asthma symptoms and airway hyperresponsiveness in childhood. Am $\mathcal{7}$ Respir Crit Care Med 1998;158:36-41.

8 O'Byrne PM, Gauvreau GM, Wood LJ. Pharmacologic modulation of airway inflammation. Allergy 1998;53:41-7.

modulation of airway inflammation. Allergy 1998;53:41-7.
9 Venge P. Serum measurements of eosinophil cationic protein (ECP) in bronchial asthma. Clin Exp Allergy 1993, 23(Suppl 2):3-7.

10 Koller DY, Herouy Y, Gotz M, et al. Clinical value of monitoring eosinophil activity in asthma. Arch Dis Child 1995;73:413-7.

11 Rosier MJ, Bishop J, Nolan T, et al. Measurement of functional severity of asthma in children. Am F Respir Crit Care Med 1994;149:1434-41.

12 Bland JM, Altman DG. Statistical methods for assessing agreement between two methods of clinical measurement. Lancet 1986;i:307-10.

13 Kirkwood TBL. Geometric means and measures of dispersion. Biometrics 1979;35:908-9.

14 Spanevello A, Migliori GB, Sharara A, et al. Induced sputum to assess airway inflammation: a study of reproducibility. Clin Exp Allergy 1997;27:1138-44.

15 De-Gouw HW, Smits HH, Sont JK, et al. Repeatability of cellular and soluble markers of inflammation in induced sputum from patients with asthma. Eur Respir f 1996;9: 2441-7.

16 Pizzichini E, Pizzichini MM, Efthimiadis A, et al. Indices of airway inflammation in induced sputum: reproducibility and validity of cell and fluid-phase measurements. $A m \mathcal{F}$ Respir Crit Care Med 1996;154:308-17.
17 Ronchi MC, Piragino C, Rosi E, et al. Do sputum Ronchi MC, Piragino C, Rosi E, et al. Do sputum eosinophils and ECP relate

18 Efthimiadis A, Pizzichini MM, Pizzichini E, et al. Induced sputum cell and fluid-phase indices of inflammation: comparison of treatment with dithiothreitol vs phosphatebuffered saline. Eur Respir F 1997;10:1336-40.

19 Pizzichini E, Pizzichini MM, Efthimiadis A, et al. Measurement of inflammatory indices in induced sputum: effects of selection of sputum to minimize salivary contamination. Eur Respir f 1996;9:1174-80.

20 Piacentini GL, Bodini A, Costello S, et al.Exhaled nitric oxide and sputum eosinophil markers of inflammation in asthmatic children. Eur Respir $\mathcal{F}$ 1999;13:1386-90.

21 Johnston SL, Sanderson G, Pattemore PK, et al. Use of polymerase chain reaction for diagnosis of picornavirus infection in subjects with and without respiratory symptoms. F Clin Microbiol 1993;31:111-7.

22 Koller DY, Herouy Y, Gotz M, et al. Clinical value of monitoring eosinophil activity in asthma. Arch Dis Child 1995;73:413-7.

23 Ferguson AC, Vaughan R, Brown H, et al. Evaluation of serum eosinophilic cationic protein as a marker of disease activity in chronic asthma. F Allergy Clin Immunol 1995;95: 23-8.

24 Vanto T, Koskinen P. Serum eosinophil cationic protein in the evaluation of asthma severity in children. Allergy 1998; 53:415-9.

25 Grootendorst DC, Sont JK, Willems LN, et al. Comparison of inflammatory cell counts in asthma: induced sputum vs bronchoalveolar lavage and bronchial biopsies. Clin Exp Allergy 1997;27:769-79.

26 Iredale MJ, Wanklyn SA, Phillips IP, et al. Non-invasive assessment of bronchial inflammation in asthma: no correlation between eosinophilia of induced sputum and bronchial responsiveness to inhaled hypertonic saline. Clin Exp Allergy 1994;24:940-5.

27 Crimi E, Spanevello A, Neri M, et al. Dissociation between airway inflammation and airway hyperresponsiveness in allergic asthma. Am 7 Respir Crit Care Med 1998;157:4-9.

28 Grootendorst DC, van den Bos JW, Romeijn JJ, et al. Induced sputum in adolescents with severe stable asthma. Safety and the relation of cell counts and eosinophil cationic protein to clinical severity. Eur Respir f 1999;13: 